\title{
Article \\ Sensitivity Test of Jet Velocity and Void Fraction on the Prediction of Rise Height and Performance of a Confined Plunging Liquid Jet Reactor
}

\author{
Bader S. Al-Anzi *(D) and Jenifer Fernandes
}

check for updates

Citation: Al-Anzi, B.S.; Fernandes, J. Sensitivity Test of Jet Velocity and Void Fraction on the Prediction of Rise Height and Performance of a Confined Plunging Liquid Jet Reactor. Processes 2022, 10, 160. https:// doi.org/10.3390/pr10010160

Academic Editor: Nicolas Dietrich

Received: 14 November 2021

Accepted: 11 January 2022

Published: 13 January 2022

Publisher's Note: MDPI stays neutral with regard to jurisdictional claims in published maps and institutional affiliations.

Copyright: (C) 2022 by the authors. Licensee MDPI, Basel, Switzerland. This article is an open access article distributed under the terms and conditions of the Creative Commons Attribution (CC BY) license (https:// creativecommons.org/licenses/by/ $4.0 /)$
Environment Technology Management, College of Life Sciences, Kuwait University, P.O. Box 5969, Safat 13060, Kuwait; jenijess@hotmail.com

* Correspondence: bader.alanzi@ku.edu.kw; Tel.: +965-9788-5589

\begin{abstract}
Jet velocity is an important parameter affecting the air entrainment rate of plunging liquid jet processes. While the vast majority of researchers have investigated the effect of jet velocity, only a few of them considered the effect of jet length in calculating the jet velocity at impingement point. This study investigates the difference $(\Delta \mathrm{V})$ between the jet velocity at the inception of the nozzle $\left(\mathrm{V}_{\mathrm{j}}\right)$ and the impingement point $\left(\mathrm{V}_{\mathrm{L}}\right)$ for a range of operating conditions. Furthermore, bubble voidage inside the downcomer, another critical parameter in plunging jets, is estimated using three different voidage equations incorporated inside a momentum balance model to predict the two-phase elevation level $\left(\mathrm{H}_{\mathrm{R}}\right)$ inside the downcomer. Results showed that $\Delta \mathrm{V}$ is significant $\left(\mathrm{V}_{\mathrm{L}}>\mathrm{V}_{\mathrm{j}}\right)$, especially at low jet flow rates and high jet lengths. Generally, the momentum balance model predicted the $\mathrm{H}_{\mathrm{R}}$ well, and its prediction improves with downcomer diameter. Given that, the model still needs to be refined for more accuracy for a wide range of operating conditions.
\end{abstract}

Keywords: multiphase flow; rise height; confined plunging jet reactor; aeration; dilution

\section{Introduction}

In nature, gas entrainment occurs due to the impingement of a falling liquid into a receiving water body like in waterfalls, rivers, and streams that result in a dispersion of air bubbles into the water body, which ultimately results in self-purification or reaeration of the water body [1]. In fact, in environmental scenarios like breaking waves, the aeration rate can increase 200 times since many air bubbles entrain into the wave, and there is a tremendous increase in the air-water interfacial area [2]. Entrainment by plunging jets is a phenomenon that is advantageous in many applications such as aerobic wastewater treatment, fermentation processes, brine dilution, oxygen dissolution, air pollution abatement, and froth flotation as it achieves gas absorption and diffusion by bringing two phases in contact [1,3-5]. The mass transfer between the two phases can be significantly increased if large interfacial areas for contact are provided, i.e., the most common method is by dispersing the gas phase as fine bubbles into the liquid phase [6] However, in some instances, such as the formation of gas bubbles when molten liquids are poured into a container, gas entrainment is undesirable and must be avoided [1].

Among all the gas-liquid reactors, the jet mixing reactors, i.e., those with contacting surfaces like nozzles, venturies, or ejectors, are gaining more popularity because of the high interfacial areas for the gas and liquid contact and rigorous mixing of the liquid content at a low cost. In these reactors, the fluid's kinetic energy is used to achieve dispersion and mixing between the phases.

The concept of plunging liquid has been around for about five decades (since the 1970s). It started out as an unconfined plunging liquid jet reactor (UPLJR) [7-14] Later on, a confined PLJR (CPLJR), was introduced to overcome the limited penetration depth provided by the UPLJR by introducing a confining tube [15-19]. The CPLJR enhanced 
the oxygen dissolution into the liquid by increasing bubble-liquid contact time (residence time) due to an increase in bubble penetration depth at no or low cost. In 2007, Al-Anzi introduced a novel system of CPLJR incorporating an annular airlift column to dilute the almost saturated liquid ejecting from the base of a long downcomer in the CPLJR system with fresh liquid to enable further mass transfer.

Furthermore, the PLJR is an excellent gas-liquid contactor as it is energy efficient and can achieve sufficiently high mass transfer rates. This is possible since it can entrain gas bubbles into a liquid phase at low costs (operating and capital costs) $[3,4,18]$ The liquid phase ejects from a nozzle, thereby forming a jet, which then falls through ambient headspace and plunges into the surface of a receiving pool of the same liquid. As it falls through the headspace, it entrains air along with it, thus promoting aeration of the two phases. If the liquid falls into the receiving body through a confined tube (downcomer), this system is called the confined liquid jet reactor (Figure 1b). In contrast, the reactor without a confining tube is called an unconfined plunging jet reactor (Figure 1a) or simply a plunging jet reactor. When the impact velocity of the impinging jet is greater than the critical jet velocity, air bubbles are entrained in the liquid [20]. The air that is entrained by a plunging jet gets dispersed into the receiving body, but the penetration depth of the bubbles is small since the jet spreads across the receiving water, reducing the contact time of the bubble. However, by adding a confining tube (CPLJR), the downcomer surrounds the liquid jet, which helps to maintain the liquid superficial velocity of the jet, which then helps to carry the entrained bubbles to larger depths.

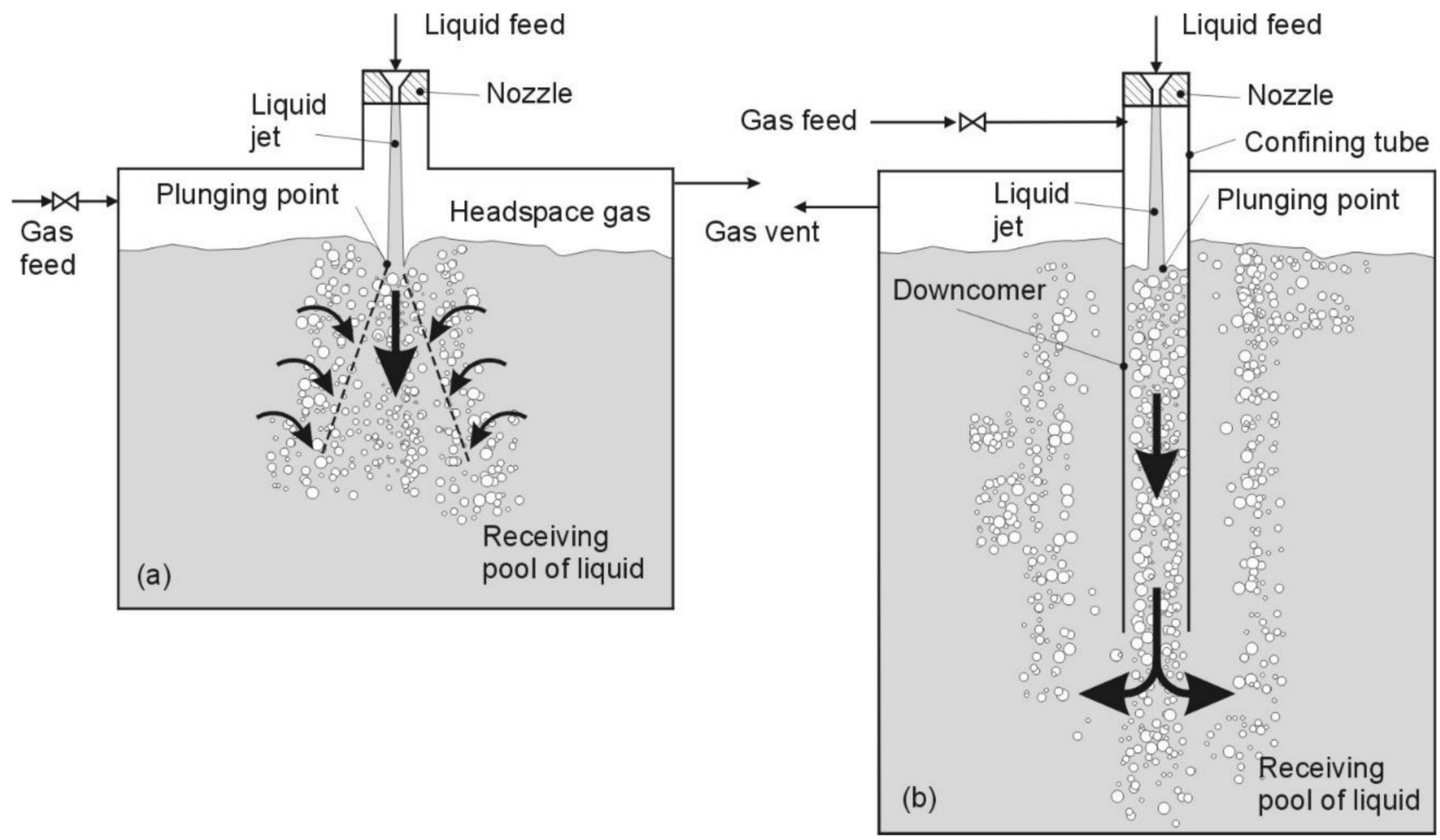

Figure 1. (a) An unconfined plunging jet system (b) the same jet surrounded by a confining downcomer column [4].

Results showed that the liquid leaving the end of a long downcomer in a CPLJR was almost saturated with oxygen $(>90 \%)$ [21]. This was resolved by introducing an annulus around the confining tube, as shown in Figure 2 which brings fresh unaerated water from the surrounding liquid in contact with the bubbles leaving with saturated liquid from the base of the downcomer to promote further mass transfer at no extra cost [3]. 


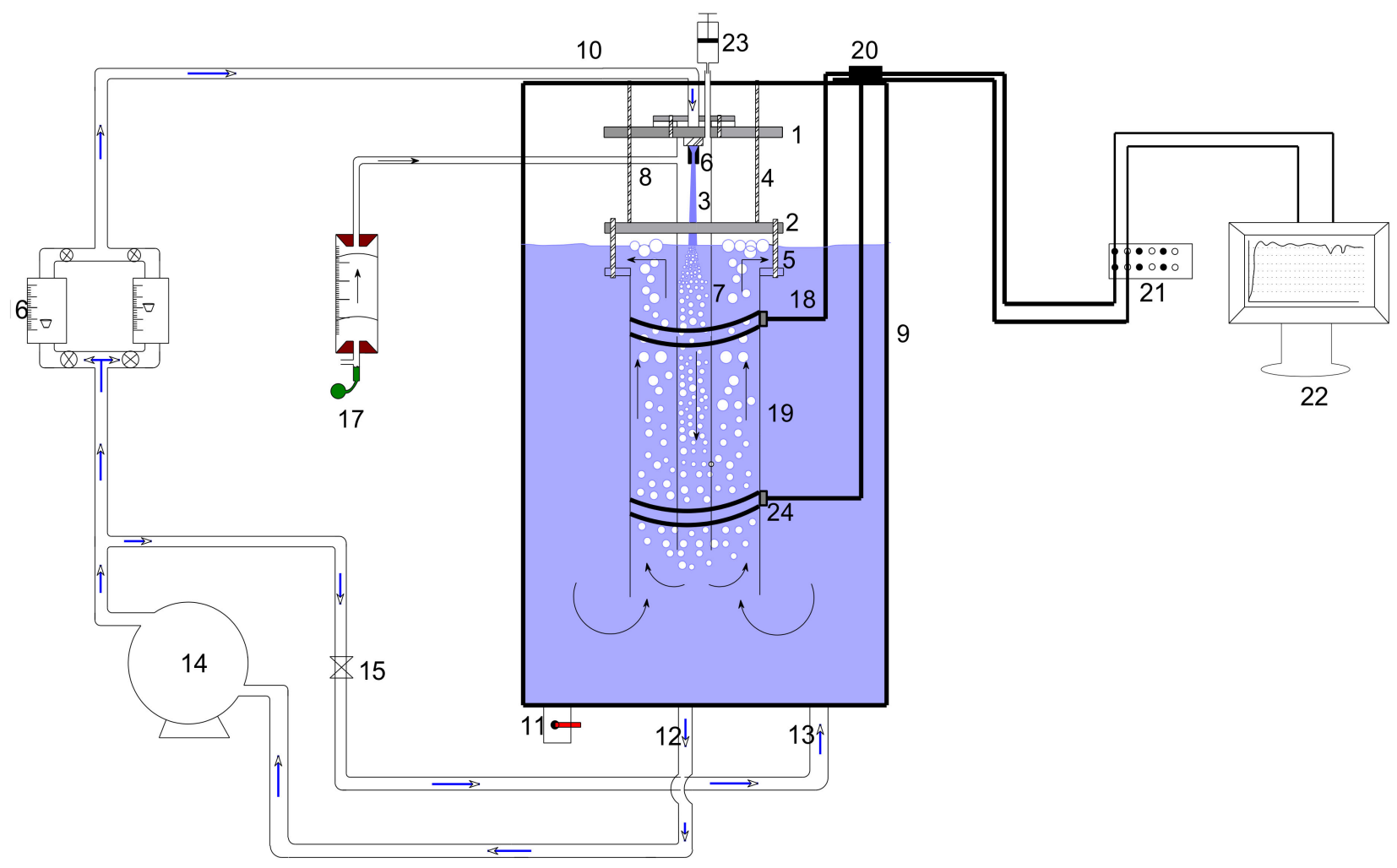

Figure 2. Schematic diagram of the air-lift column in the confined plunging liquid jet reactor (CPLJR). (1) top flange; (2) bottom flange; (3) liquid jet; (4) supporting rods; (5) riser rods; (6) nozzle; (7) downcomer; (8) air tapping; (9) water tank; (10) water supply; (11) drain; (12) recycled water; (13) bypass; (14) pump; (15) valve; (16) rotameter; (17) bubble meter; (18) wires; (19) annulus; (20) connection point; (21) amplifier; (22) PC; (23) injecting salt by syringe; (24) electrode rings [3].

Plunging liquid jets have multiple applications in industries and are primarily used when two-phase mixing is required. They are of great use in aerobic wastewater treatment plants, in froth flotation, and can also be used in desalination outfalls [4]. Recently, a group of researchers from Kuwait University and MIT explored the idea of utilizing such technology (both confined and unconfined) as a brine dispenser and for oxygen dissolution [5,22]. Another application of using this technology is using an airlift column that surrounds the confining tube (Figure 2). The role of this annulus is to collect the upward gas-liquid flow that exits from the bottom of the downcomer resulting in entraining pure freshwater from the surrounding through the bottom of the annulus in the upward direction. This is mixed with the saturated liquid from the bottom of the confining tube for additional mass transfer [3].

The mechanism and behavior of the plunging jets have been extensively investigated by many authors. Parameters such as jet lengths $\left(L_{j}\right)$, nozzle diameter $\left(d_{n}\right)$, jet velocity $\left(V_{j}\right)$, fluid properties, and downcomer diameter $\left(D_{c}\right)$ affect the volumetric gas entrainment rate $\left(Q_{\mathrm{a}}\right)$, and various studies have been conducted in the past to design an optimal plunging jet reactor $[2-5,7,9,11,18,23,24]$. The velocity of the jet is one of the primary variables that significantly affects the performance of a PLJR. Many researchers have justified how the jet velocity and its interaction with the receiving body are significant in air entrainment. Chanson and Lee [25]. even talked in their report about how the bubble entrainment is critically dependent on two factors-the impact velocity and the impact angle. Wang et al. [26] discussed that air entrainment happens only when the plunging velocity exceeds the critical velocity point. In their research study, Miwa et al. [24]) stated that the entrainment rates differ with jet velocity ranges and have given two different correlations for such cases (when $V_{j}$ is less than $5 \mathrm{~m} / \mathrm{s}$ and when $V_{j}$ is less than $10 \mathrm{~m} / \mathrm{s}$ but greater than $5 \mathrm{~m} / \mathrm{s}$ ). Dimensions of the nozzle and the diameter of the confining tube 
are other secondary factors to consider, along with the effect of jet velocity. In addition to this, Chanson et al. [2]. also pointed out that the jet length $\left(\mathrm{L}_{\mathrm{j}}\right)$ is another critical variable responsible for creating this momentum impact for a deeper penetration level and contributes to the jet velocity at the impingement point $\left(\mathrm{V}_{\mathrm{L}}\right)$.

The voidage is a vital parameter to understand the liquid-gas interaction in the column and is the other variable of interest in our work [27]. The amount of bubbles in a two-phase system can be represented by their voidage or void fraction (n). The simplest approximation of voidage is when the air dis-entrainment rate is not accounted for, and the gas void fraction is considered simply to be a fraction of the total mixture $\left(\mathrm{Q}_{2}\right)$.

$$
\begin{gathered}
\text { Since } \mathrm{Q}_{\mathrm{a}}=\mathrm{n}_{2} \text { and } \mathrm{Q}_{2}=\mathrm{Q}_{\mathrm{a}}+\mathrm{Q}_{\mathrm{j}} \\
\mathrm{n}_{1}=\frac{\mathrm{Q}_{\mathrm{a}}}{\left(\mathrm{Q}_{\mathrm{a}}+\mathrm{Q}_{\mathrm{j}}\right)}
\end{gathered}
$$

where $Q_{a}$ and $Q_{j}$ represent the volumetric flowrate of gas and liquid, respectively.

However, Al-Anzi [3] stressed that gas void fraction could not be a simple gas ratio in the mixture of liquid and gas flowrates as the slip velocity between the phases, and the effects caused due to the non-uniform flows and the concentration distribution must be considered. Zuber and Findalay [26] have given an equation to quantify the gas void fraction which considered these factors. It was Clark and Flemmer [28] who used that equation and simplified it to predict the voidage accurately in a downcomer. Their equation is as follows:

$$
\mathrm{n}_{2}=\frac{\mathrm{Q}_{\mathrm{a}}}{\mathrm{C}_{0}\left(\mathrm{Q}_{\mathrm{j}}+\mathrm{Q}_{\mathrm{a}}\right)-\mathrm{U}_{0} \mathrm{Ac}}
$$

where $C_{0}$ is a constant whose value equals $1.16 \mathrm{U}_{\mathrm{o}}$ is the bubble rise velocity, and $\mathrm{A}_{\mathrm{c}}$ is the area of the downcomer [28].

This paper discusses the effect of the jet length $\left(\mathrm{L}_{\mathrm{j}}\right)$ on jet velocity for a range of jet velocity values by calculating the differences between the jet velocities $(\Delta \mathrm{V})$ at the nozzle inception $\left(V_{j}\right)$, at rise height inside the downcomer $\left(V_{R}\right)$, and at the impingement point $\left(V_{L}\right)$. The current study also covers the effect of bubble voidage (n) on the rise height of gas-liquid inside the downcomer $\left(\mathrm{H}_{\mathrm{R}}\right)$. This is achieved by incorporating three voidage equations $\left(\mathrm{n}_{1}, \mathrm{n}_{2}\right.$, and $\left.\mathrm{n}_{3}\right)$ into a momentum mass balance to predict $\mathrm{H}_{\mathrm{R}}$ theoretically and compare it against local experimental data obtained in the College of Life Sciences laboratory at Kuwait University.

\section{Model Calculations}

\subsection{Jet Velocity along the Jet Length}

Jet length $\left(\mathrm{L}_{\mathrm{j}}\right)$, or the length that the jet has to vertically travel before it reaches the impact or impingement point, is a significant parameter for design, as it is responsible for the air entrainment rate in the PLJR process. Al-Anzi [3,4] have mentioned that as the jet length increases, the disturbances on the jet length also increases since the jet is exposed to air for a longer time since its inception. Along with the jet length, the nature of the falling jet (laminar or turbulence) can affect the amount of air entrained. Some of the previous studies [3] have not considered the effect of jet length on the jet velocity and kept it at a constant value in the experiments due to either short jet length or high jet velocities; thus, they did not have significant $\mathrm{H}_{\mathrm{R}}$.

With regards to the jet velocity parameter (Figure 3c), there are two groups of researchers. The early researchers focused on the velocity of the jet at nozzle point $\left(V_{j}\right)$ in their correlations and calculations for air entrainment [3,18]. Recently, researchers have shown that the velocity at impingement point (that could be the velocity at the receiving body surface $\left(\mathrm{V}_{\mathrm{L}}\right)$ or velocity at the rise height surface $\left.\left(\mathrm{V}_{\mathrm{R}}\right)\right)$ is significantly higher than that at the nozzle inception, especially at low jet velocity and high jet length [24,29-31]. The $V_{L}$ velocity is the velocity effect coupled with the gravitational forces due to jet length $L_{j}$, 
which adds to the momentum of the flowing jet, and is worth considering in the equations used to calculate air entrainment rates. From Qu et al. [29] $V_{R}$ is expressed as Equation (4) given below:

$$
\mathrm{V}_{\mathrm{R}}=\sqrt{\mathrm{V}_{\mathrm{j}}{ }^{2}+2 \mathrm{~g}\left(\mathrm{~L}_{\mathrm{j}}-\mathrm{H}_{\mathrm{R}}\right)}
$$
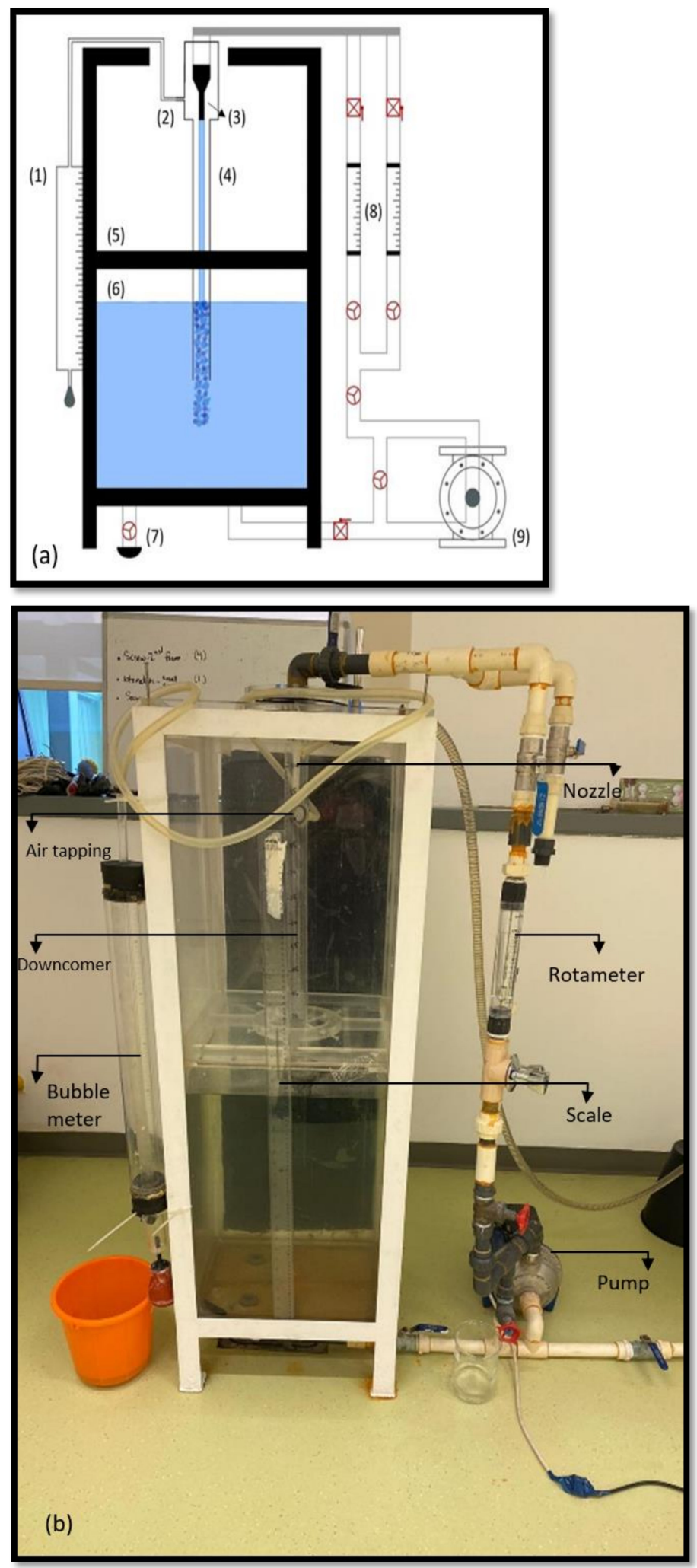

Figure 3. Cont. 

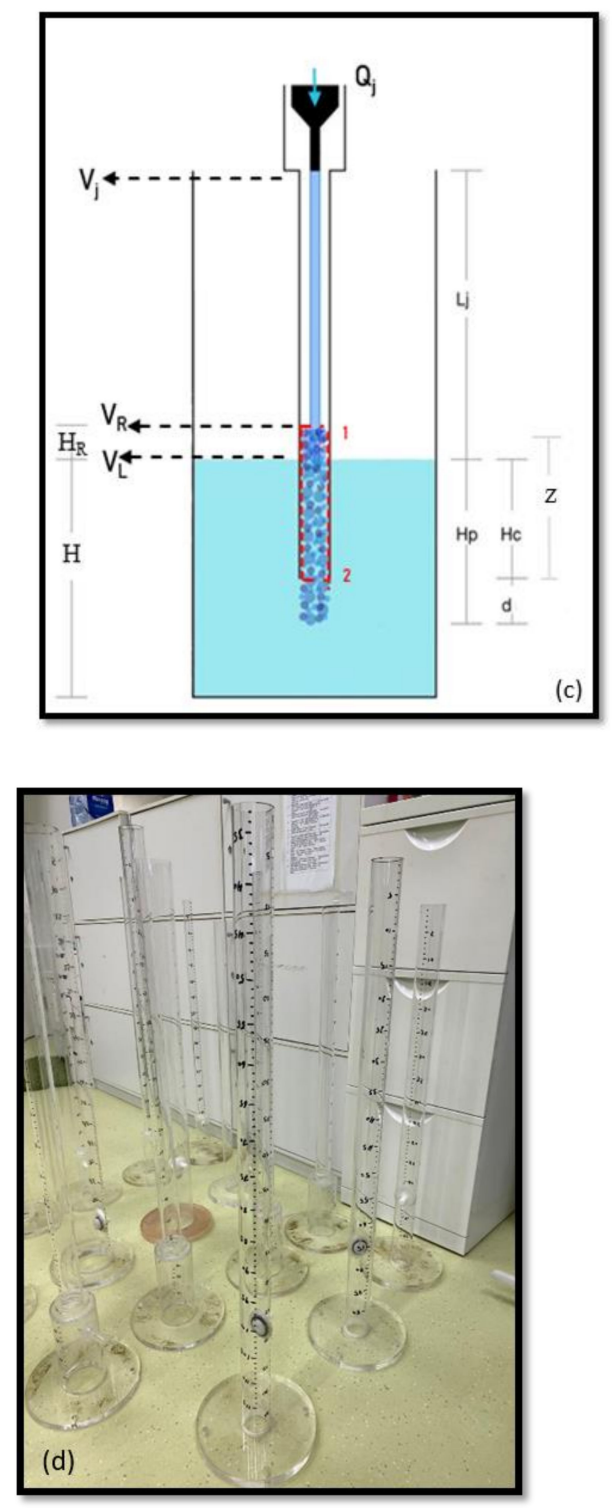

Figure 3. (a) The schematic of the CPLJR unit illustrating the different parts: (1) bubble meter, (2) air tapping, (3) nozzle, (4) downcomer, (5) inner frame, (6) water tank, (7) drain outlet, (8) rotameters, and (9) pump; (b) the CPLJR unit in the Kuwait University laboratory; (c) schematic of the CPLJR model showing the variables used in the momentum model study; (d) the scaled downcomers used in this study.

Similarly, $\mathrm{V}_{\mathrm{L}}$ is expressed as Equation (5) given below:

$$
\mathrm{V}_{\mathrm{L}}=\sqrt{\mathrm{V}_{\mathrm{j}}^{2}+2 \mathrm{~g}\left(\mathrm{~L}_{\mathrm{j}}\right)}
$$

\subsection{Voidage Formulae}

The amount of air entrained in a liquid or the voidage fraction of air inside the liquid is another parameter that is crucial for determining the air entrainment rate and can be calculated using three voidage equations described in detail below. Firstly, we consider the most straightforward equation to define voidage: the volume fraction of the bubbles in a total mixture of air and liquid, which is the Equation (2):

$$
\mathrm{n}_{1}=\frac{\mathrm{Q}_{\mathrm{a}}}{\left(\mathrm{Q}_{\mathrm{a}}+\mathrm{Q}_{\mathrm{j}}\right)}
$$


Secondly, we consider the approximation that Clark and Flemmer [28] considered and used in their equation:

$$
\mathrm{n}_{2}=\frac{\mathrm{Q}_{\mathrm{a}}}{\mathrm{C}_{0}\left(\mathrm{Q}_{\mathrm{j}}+\mathrm{Q}_{\mathrm{a}}\right)-\mathrm{U}_{0} \mathrm{Ac}}
$$

To further simplify the above equation, we considered a voidage equation where we consider the disentrainment effect $\mathrm{U}_{0} \mathrm{Ac}$ as negligible.

$$
\mathrm{n}_{3}=\frac{\mathrm{Q}_{\mathrm{a}}}{\mathrm{C}_{0}\left(\mathrm{Q}_{\mathrm{j}}+\mathrm{Q}_{\mathrm{a}}\right)}
$$

\subsection{Momentum Balance}

In the current study, a hydraulic model was developed to describe the confined plunging jet reactor performance using momentum and volume balances, based on the model outlined by Cumming et al. [5]. This model was then used to predict the rise height of the bubbles in the downcomer $\left(\mathrm{H}_{\mathrm{R}}\right)$ and compare it with experimental data.

A schematic and an actual impression of the CPLJR system utilized in the current work are shown in Figure $3 a, b$, respectively. Figure $3 c$ illustrates the variables used in the momentum study, where $Q_{j}$ flowrate of the jet, and $Q_{2}$ is the combined flow rate of air and liquid exiting from the bottom of the downcomer; $V_{j}$ is the jet velocity at the nozzle, $V_{R}$ is the jet velocity at the rise height $\left(\mathrm{H}_{R}\right)$, and $V_{L}$ is the jet velocity at the impingement point; $V_{1}$ and $V_{2}$ are the liquid velocities at Sections 1 and 2 , respectively, where $V_{2}=\frac{Q_{j}}{A_{c}(1-n)} ; L_{j}$ is the jet length, and $\mathrm{H}_{\mathrm{c}}$ is the downcomer submergence, $\mathrm{D}_{\mathrm{c}}$ is the diameter of the downcomer, $\mathrm{A}_{\mathrm{c}}$ is the cross-sectional area of the downcomer and $\mathrm{n}$ is the bubble voidage within the downcomer. The density of water is represented as $\rho_{j}, \rho_{\mathrm{w}}$ is the density of receiving water, and $\rho_{\mathrm{aj}} \approx(1-\mathrm{n}) \rho_{\mathrm{j}}$ is the density of the air-water mixture within the downcomer. $\mathrm{P}_{1}$ is the pressure at Section $1, P_{2}$ is the pressure at Section 2, and $Q_{a}$ is the air flowrate which is calculated by multiplying the cross-sectional area of the inner diameter of the bubble meter and the velocity of air (which is found out by dividing the distance of bubble rise in the bubble column by the time taken throughout the rise).

Volume and momentum balances:

$$
\mathrm{Q}_{2}=\mathrm{Q}_{\mathrm{a}}+\mathrm{Q}_{\mathrm{j}}
$$

and

$$
\left(P_{2}-P_{1}\right) A_{c}+\left(-\frac{d P}{d Z} Z A_{c}\right)-Z \rho_{a j} g A_{c}=\rho_{j} Q_{j}\left\{v_{1}-v_{2}\right\}
$$

where $\mathrm{Z}=\mathrm{H}_{\mathrm{R}}+\mathrm{H}_{\mathrm{C}}$

$$
\left(P_{2}=P_{1}+\rho_{w} g Z\right)
$$

Substituting Equations (9) and (10) in Equation (8), yields,

$$
\rho_{\mathrm{w}} \mathrm{gA}_{\mathrm{c}}\left(\mathrm{H}_{\mathrm{R}}+\mathrm{H}_{\mathrm{c}}\right)+\left(-\frac{\mathrm{dP}}{\mathrm{dZ}}\left(\mathrm{H}_{\mathrm{R}}+\mathrm{H}_{\mathrm{c}}\right) \mathrm{A}_{\mathrm{c}}\right)-\rho_{\mathrm{j}}(1-\mathrm{n}) \mathrm{g}\left(\mathrm{H}_{\mathrm{R}}+\mathrm{H}_{\mathrm{c}}\right) \mathrm{A}_{\mathrm{c}}=\rho_{\mathrm{j}} \mathrm{Q}_{\mathrm{j}}\left\{\mathrm{v}_{1}-\mathrm{v}_{2}\right\}
$$

where

$$
-\frac{\mathrm{dP}}{\mathrm{dZ}}=\frac{\left\{4 \mathrm{C}_{\mathrm{fd}}\left(\frac{\mathrm{Q}_{\mathrm{a}}}{\mathrm{A}_{\mathrm{c}}}+\frac{\mathrm{Q}_{\mathrm{j}}}{\mathrm{A}_{\mathrm{c}}}\right)^{2} \rho_{\mathrm{aw}}\right\}}{2 \mathrm{D}_{\mathrm{c}}}(\text { Cumming et al. 2002) }
$$

where $C_{\mathrm{fd}}=0.079 \operatorname{Re}^{-0.25}$

And $\operatorname{Re}=\frac{\left\{\frac{Q_{a}}{A_{c}}+\frac{Q_{j}}{A_{c}}\right\} D_{c} \rho_{a w}}{\mu_{f}}$ (Cumming et al. 2002).

$H_{R}$ can be predicted from Equation (11). 


\section{Experimental Work}

\subsection{Description of Our Apparatus}

The confined plunging liquid jet apparatus constructed at the local laboratory in Kuwait University (College of Life Sciences) is shown in Figure 3b. A centrifugal pump recirculated tap water from the bottom of a $1.25 \times 0.5 \times 0.5 \mathrm{~m}^{3}$ reservoir and fed it through a nozzle in the form of a liquid jet. A rotameter was used to measure the liquid flow rates of 9 , 15 , and $30 \mathrm{LPM}$, and two nozzle diameters of $10 \mathrm{~mm}$ and $8 \mathrm{~mm}$ were also used in the present study. Jet lengths (distance between the receiving pool and the nozzle through which the jet ejects) were in the range from 200 to $600 \mathrm{~mm}$. Downcomers of different diameters $\left(D_{c}\right)$ were used in the study $\left(D_{c}=2.5 \mathrm{~cm}, 4.4 \mathrm{~cm}, 6.4 \mathrm{~cm}, 7.4 \mathrm{~cm}\right.$ and $\left.9.4 \mathrm{~cm}\right)$. The downcomer submergence $\left(\mathrm{H}_{\mathrm{c}}\right)$ was also varied from $5 \mathrm{~cm}$ to $40 \mathrm{~cm}$. Volumetric air entrainment rate, $Q_{a}$, was measured adopting the same technique employed by Al-Anzi [3,4] utilizing a soap bubble meter. This soap bubble meter is a cylindrical tube having an inner diameter of 74 $\mathrm{mm}$ and is $1000 \mathrm{~mm}$ long. The bubbles were generated using a soap solution mixture of $10 \%$ household detergent, $5 \%$ glycerin $(5 \%)$, and the rest is water. While the CPLJR reactor is in progress, the volume of air entering the reactor is indicated by the bubble formation inside the bubble meter. The time that the bubble takes to travel a certain distance (in this case $X=40 \mathrm{~cm}$ ) is noted and the velocity of the bubble is determined. The volumetric flowrate is then deduced by multiplying this bubble velocity to the cross-sectional area of the bubble meter.

\subsection{Jet Length $\left(L_{j}\right)$ and Rise Height $\left(H_{R}\right)$ Experimental Measurement}

All the downcomers were scaled so that the distance between the nozzle tip and the water surface was measured easily during the run (Figure $3 d$ ). $L_{j}$ was adjusted by controlling the receiving pool level inside the tank. During the experimental work, a rise height $\left(\mathrm{H}_{\mathrm{R}}\right)$ of the two-phase mixture was noticed inside the downcomer, especially for small downcomer diameter. $\mathrm{H}_{\mathrm{R}}$ fluctuated due to the operating conditions prevailing during the plunging jet operation. For each run, three $\mathrm{H}_{\mathrm{R}}$ measurements were recorded and averaged for the final $\mathrm{H}_{\mathrm{R}}$ value.

\section{Results and Discussion}

\subsection{Significance of Jet Length $\left(L_{j}\right)$ and $\left(H_{R}\right)$ on Final Water Jet Velocity, $V_{L}$}

To illustrate the effect of $L_{j}$ and $H_{R}$ on $V_{j}, V_{R}$, and $V_{L}$, model graphs (Figures 4 and 5) called "V vs. $Q_{j}$ map" were generated for this purpose. Values of $V_{j}$ were selected to match the experimental ones and then used to calculate $V_{L}$ and $V_{R}$ using Equations (4) and (5). Figure 4 shows the effect of $L_{j}$ and $H_{R}$ on $V_{j}, V_{R}$, and $V_{L}$ at $L_{j}=20 \mathrm{~cm}$. Furthermore, Figure 5 shows the same effect for other $L_{j} s(20,40$ and $60 \mathrm{~cm})$, wherein a wide range of $L_{j}, H_{R}$, and $\mathrm{Q}_{j}$ values as well as some experimental data points of previous authors were shown.

Figure 4 clearly shows that for a fixed $L_{j}$ and low jet velocity $\left(V_{j}\right)$, the difference between $V_{L}$ and $V_{j}$ is significant $\left(\Delta V_{L j}=V_{L}-V_{j}\right)$. However, this difference decreases as $V_{j}$ increases to become negligible at high $\mathrm{V}_{j}$ for a fixed $\mathrm{L}_{\mathrm{j}}$. This also applies to the difference between $V_{R}$ and $V_{j}\left(\Delta V_{R j}=V_{R}-V_{j}\right)$, where the effect of $V_{R}$ diminishes at small $H_{R}$. This is because of the impact of the first term $\left(\mathrm{V}_{\mathrm{j}}{ }^{2}\right)$ in Equations (4) and (5), which predominates over the other hydrostatic velocity terms $\left[2 \mathrm{gL}_{\mathrm{j}}\right.$ and $\left.2 \mathrm{~g}\left(\mathrm{~L}_{\mathrm{j}}-\mathrm{H}_{\mathrm{R}}\right)\right]$, particularly at high $\mathrm{V}_{j}$ reducing the corresponding velocity differences $\left(\Delta \mathrm{V}_{\mathrm{Lj}}\right.$ and $\left.\Delta \mathrm{V}_{\mathrm{Rj}}\right)$ as shown in Figure 4 . In contrast, $\Delta \mathrm{V}_{\mathrm{Lj}}$ and $\Delta \mathrm{V}_{\mathrm{Rj}}$ increase with $\mathrm{L}_{\mathrm{j}}$ (Figure 5), however, to a lesser extent than $\mathrm{V}_{\mathrm{j}}$. At $\mathrm{L}_{\mathrm{j}}$ $=20 \mathrm{~cm}, \Delta \mathrm{V}_{\mathrm{Lj}}$ changes from $84 \%$ to $0.8 \%$ as the velocity of jet increases, while at $\mathrm{L}_{\mathrm{j}}=60 \mathrm{~cm}$, the $\Delta \mathrm{V}_{\mathrm{Lj}}$ changes from $90 \%$ until $3 \%$ as the velocity of jet increases. As the $\mathrm{L}_{\mathrm{j}}$ increases, in this case from $20 \mathrm{~cm}$ to $60 \mathrm{~cm}$, the $\Delta \mathrm{V}_{\mathrm{Lj}}$ at the lowest flowrate point has also increased, i.e., from $84 \%$ to $90 \%$. Also, Figure 4 shows that the difference between $V_{R}$ and $V_{L}$ is negligible due to small $\mathrm{H}_{\mathrm{R}}$ compared to $\mathrm{V}_{\mathrm{j}}{ }^{2}$ (predominant term); and hence $\mathrm{V}_{\mathrm{R}}$ is not plotted in $\mathrm{V}$ vs. Qj map (Figure 5). Experimental data from selected authors were added to the " $V$ vs. $Q_{j}$ map", and some of them (Miwa et al. [24]; Current study 1, 2021; Current study 2, 2021) lay 
within the map's range; however, some lay outside the map's range (Al-Anzi [3]) due to different operating conditions.

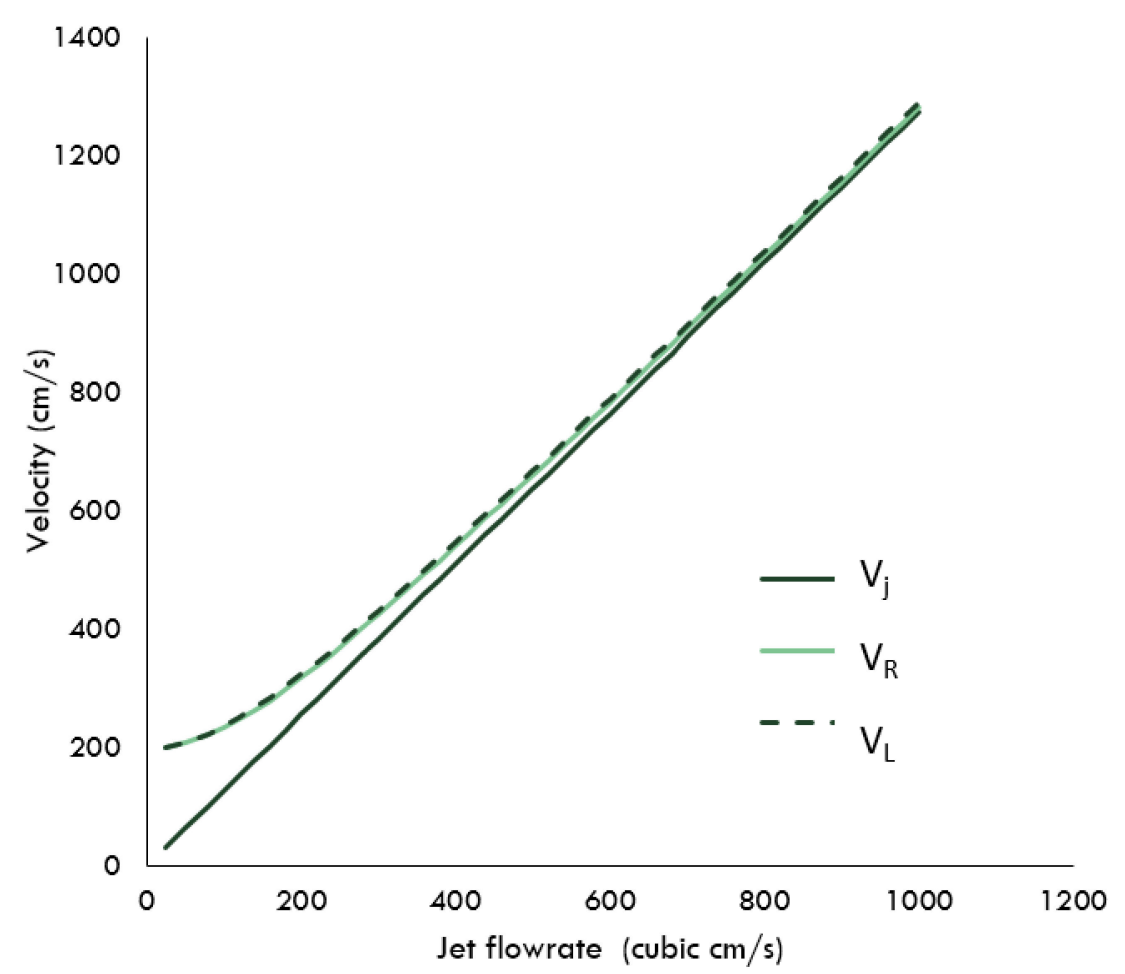

Figure 4. $V_{j}, V_{L}$, and $V_{R}$ values at $L_{j}=20$ for a wide range of $Q_{j}$ and $H_{R}$.

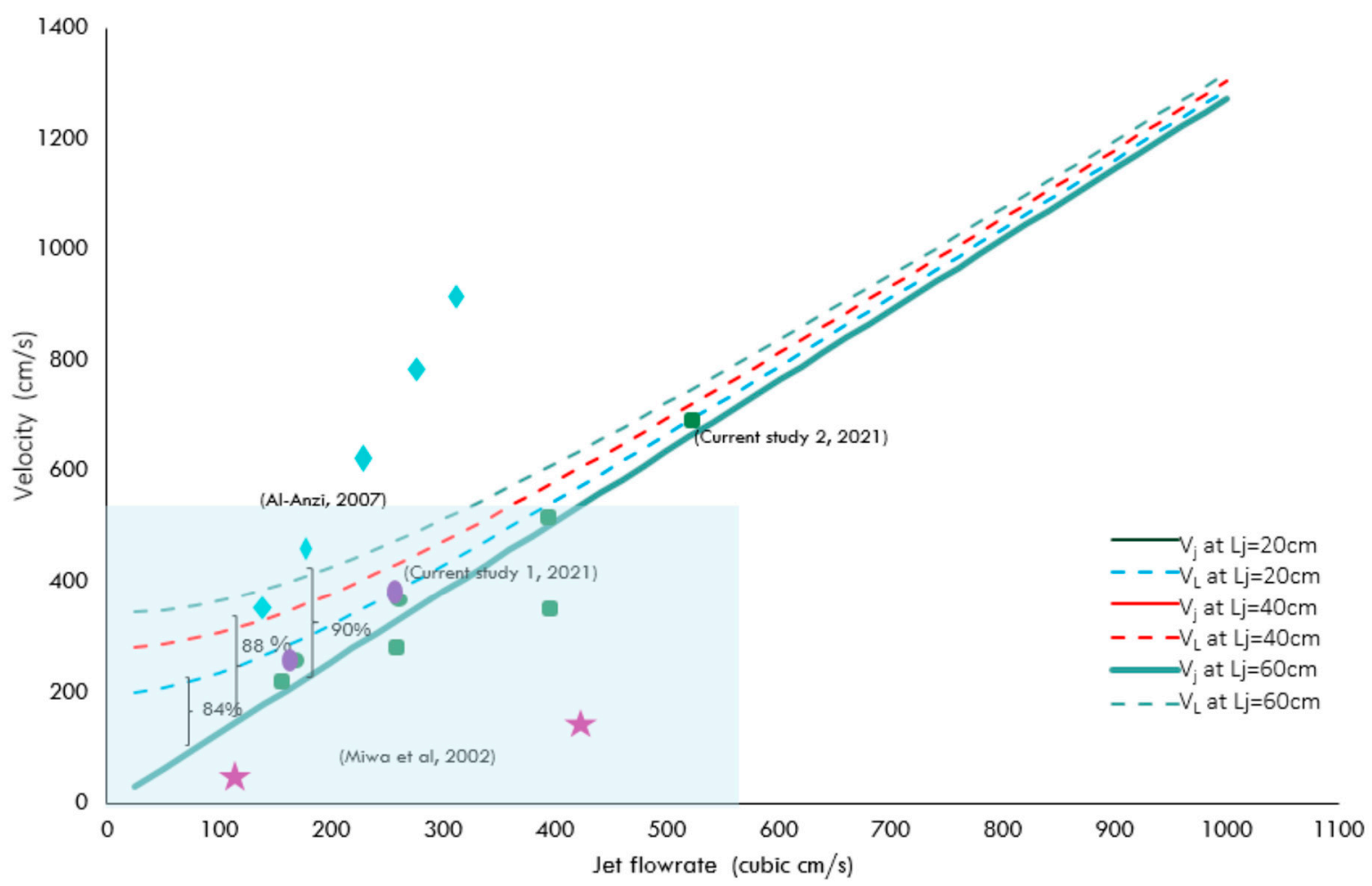

Figure 5. $\mathrm{V}$ vs. $\mathrm{Q}_{j}$ map for $\mathrm{L}_{j}=20,40$, and $60 \mathrm{~cm}$. Colored points represent experimental data from different authors' studies (Miwa et al. [24]; Al-Anzi, [3]; Current study 1, 2021; Current study 2, 2021). 
The $\Delta \mathrm{V}_{\mathrm{Lj}}$ for each $\mathrm{L}_{\mathrm{j}}$ decreases as the flow rate increases, and it is $0.8 \%, 2 \%$, and $3 \%$ for $\mathrm{L}_{\mathrm{j}}=20,40$, and 60, respectively, at high $\mathrm{Q}_{\mathrm{j}}$ values.

The foregoing facts were beneficial in determining whether $\Delta \mathrm{V}_{\mathrm{Lj}}$ is significant for the selected range or not. The selected range for the current experimental work is indicated by the shaded area in Figure 5, which suggests that the $\mathrm{L}_{\mathrm{j}}$ effect should be included in jet velocity calculation $\left(\mathrm{V}_{\mathrm{L}}\right)$. Figure 6 illustrates the impact of $\mathrm{L}_{\mathrm{j}}$ experimentally on $\Delta \mathrm{V}_{\mathrm{Lj}}$ for jet lengths of 25,45 , and $60 \mathrm{~cm}$ and a $Q_{j}$ range of $100-600 \mathrm{~cm}^{3} / \mathrm{s}$. All sets show that the difference between $\mathrm{V}_{\mathrm{L}}$ and $\mathrm{V}_{\mathrm{j}}\left(\Delta \mathrm{V}_{\mathrm{Lj}}\right)$ decreases with jet flowrate and increases with jet length. For example, at a fixed $\mathrm{L}_{\mathrm{j}}$ of $25 \mathrm{~cm}$, when $\mathrm{Q}_{\mathrm{j}}$ increases from $167-333 \mathrm{~cm}^{3} / \mathrm{s}, \Delta \mathrm{V}_{\mathrm{Lj}}$ reduces from $42 \%$ to $13 \%$ whereas for a fixed flowrate of $\mathrm{Qj}=167 \mathrm{~cm}^{3} / \mathrm{s}$, when $\mathrm{L}_{\mathrm{j}}$ changes from 25 to $45, \Delta \mathrm{V}_{\mathrm{Lj}}$ increases from $42 \%$ to $72 \%$. This confirms that the effect of the $\mathrm{V}_{\mathrm{j}}$ term on $\Delta \mathrm{V}_{\mathrm{Lj}}$ predominates over that of $\mathrm{L}_{\mathrm{j}}$.
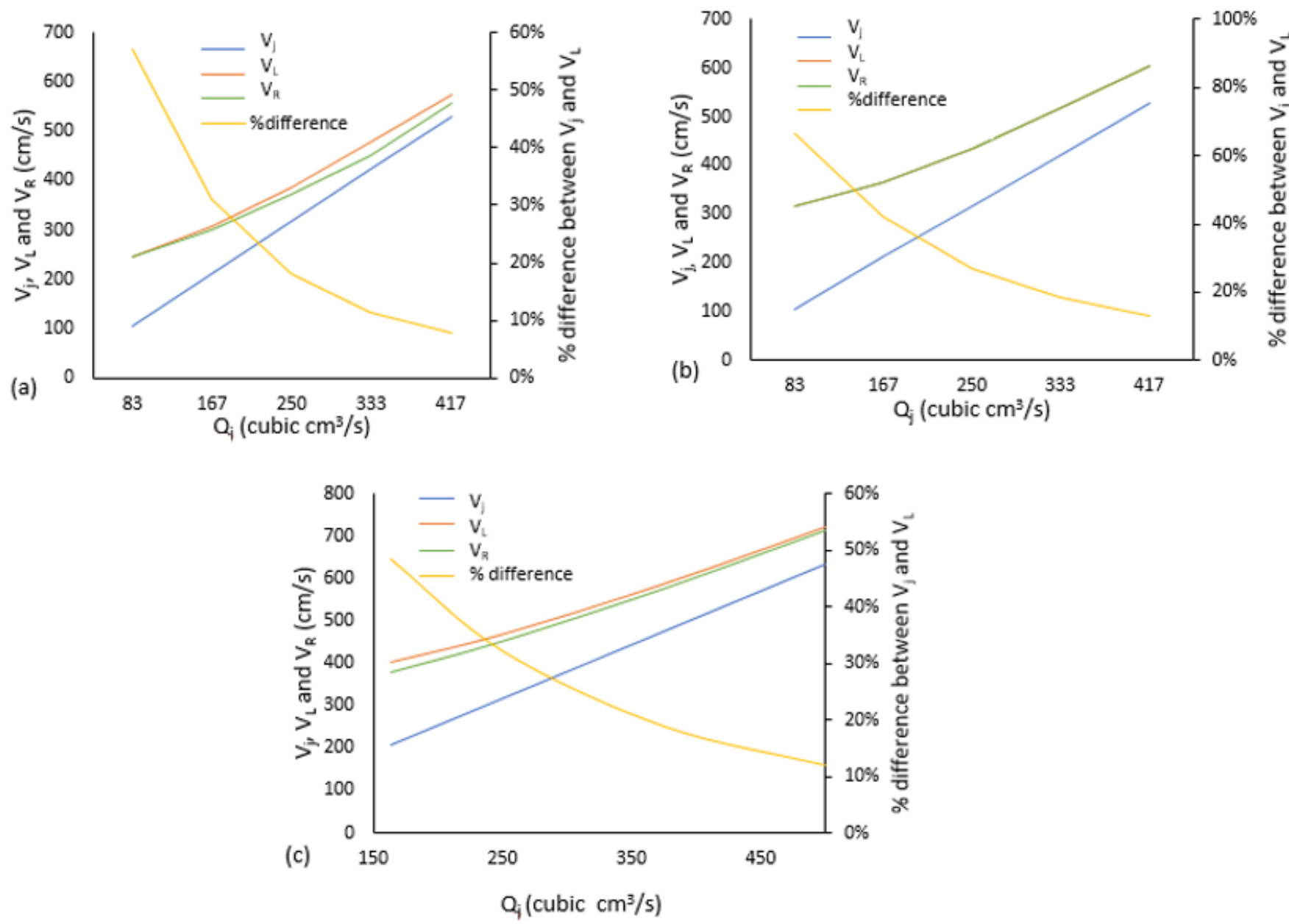

Figure 6. $\Delta \mathrm{V}_{\mathrm{Lj}}$ experimentally for $(\mathbf{a}) \mathrm{L}_{\mathrm{j}}=25 \mathrm{~cm},(\mathbf{b}) \mathrm{L}_{\mathrm{j}}=45 \mathrm{~cm},(\mathbf{c}) \mathrm{L}_{\mathrm{j}}=60 \mathrm{~cm}$.

Furthermore, a general sensitivity test is carried out experimentally to (a) measure $\mathrm{H}_{\mathrm{R}}$ over a wide range of $V_{j}$ and (b) investigate the effect of $L_{j}$ on $\Delta V_{L j}$ for a selected range of $V_{j}$.

\subsection{Confined Plunging Liquid Jet Reactor (CPLJR) Sensitivity Test}

\subsubsection{Effect of Rise Height $\left(\mathrm{H}_{\mathrm{R}}\right)$ on Jet Velocity at the Rise Height Point $\left(\mathrm{V}_{\mathrm{R}}\right)$}

Figure 7 below shows data sets for the $10 \mathrm{~mm}$ nozzle diameter and jet lengths of 25, 35, and $45 \mathrm{~cm}$ and downcomer diameter of 6.4. Since $V_{L}$ and $V_{R}$ are a function of $L_{j}$ and $H_{R}$, the initial velocity is expected to vary for each $L_{j}$, as shown in the figure. Figure 7 consistently shows that $\mathrm{H}_{\mathrm{R}}$ increases with $\mathrm{V}_{\mathrm{L}}$ or $\mathrm{V}_{\mathrm{R}}$ for all $\mathrm{L}_{\mathrm{j}} \mathrm{s}$ until it reaches a maximum and decreases except for $L_{j}$ of $45 \mathrm{~cm}$. At longer jet lengths, the superficial velocity of the liquid in the 
downcomer (momentum) is sufficient to carry most of the entrained bubbles downwards, and hence the net entrainment rate increases (Figure $7 \mathrm{~b}$ ); a negligible fraction of the bubbles are entrained and then rise up in the recirculation eddy and disentrain at the free surface. In the regions where the gas entrainment rate increases with increasing jet length, the liquid superficial velocity is greater than about $0.20-0.25 \mathrm{~m} / \mathrm{s}$, which corresponds to a typical bubble terminal velocity. Thus, a fraction of the entrained bubbles is able to descend with the downflowing liquid exiting the bottom of the downcomer that increases net entrainment rate, which reduces the formation of $\mathrm{H}_{R}$ (Figure $7 \mathrm{~b}$ ). The maximum value (hump) for $\mathrm{L}_{j}$ of 25 and $35 \mathrm{~cm}$ is reached at $\mathrm{V}_{\mathrm{j}}=4.11-4.77 \mathrm{~m} / \mathrm{s}$, respectively. This slight variation is due to the $\mathrm{L}_{\mathrm{j}}$ difference. Similar trends are observed as the downcomer diameter increases including a long jet length of 45; however, the maximum $\mathrm{H}_{\mathrm{R}}$ value was not reached at the current jet velocity range because the system behaved as an unconfined system. Figure $7 \mathrm{a}$ also shows the difference between $V_{L}$ and $V_{R}$ (dotted lines), confirming that the $\mathrm{H}_{R}$ effect is negligible on the impact velocity values.
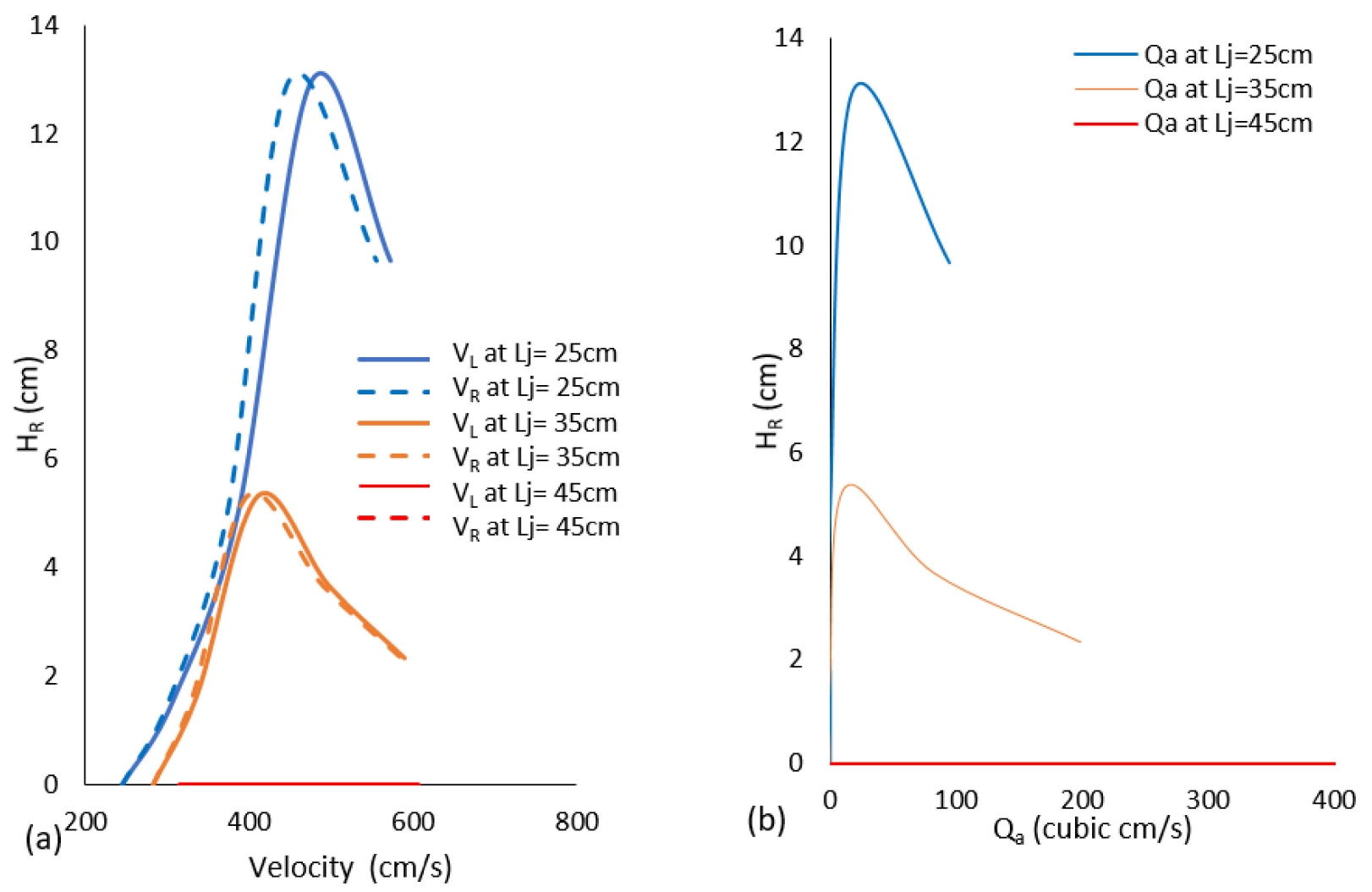

Figure 7. (a) $H_{R}$ vs. $V_{R}$ for a range of $V_{L}$ and $V_{R}$ cases $(\mathbf{b}) H_{R}$ vs. $Q_{a}$ graph for different $L_{j} s(25,35$, and $45 \mathrm{~cm}$ ) for $\mathrm{D}_{\mathrm{c}}=6.4 \mathrm{~cm}$.

\subsubsection{Effect of Jet Length $\left(\mathrm{L}_{\mathrm{j}}\right)$ on Impact Velocity $\left(\mathrm{V}_{\mathrm{R}}\right)$}

Since $V_{R}$ is the actual impact velocity of the system, although there is a negligible difference between $V_{R}$ and $V_{L}$, Figure 8 is generated to show the effect of $L_{j}$ on $V_{R}$ for low and high jet flowrates. Figure $8 a, b$ shows that $V_{R}$ is increasing linearly with $L_{j}$ for a given flowrate. Furthermore, the effect of $D_{c}$ on $V_{R}$ is not a simple monotonic relationship as there are other factors that contribute to the value of $V_{R}$. Such factors are disentrainment rate, jet length, jet flowrate, $H_{R}$ formation, and the $D_{C}$. 

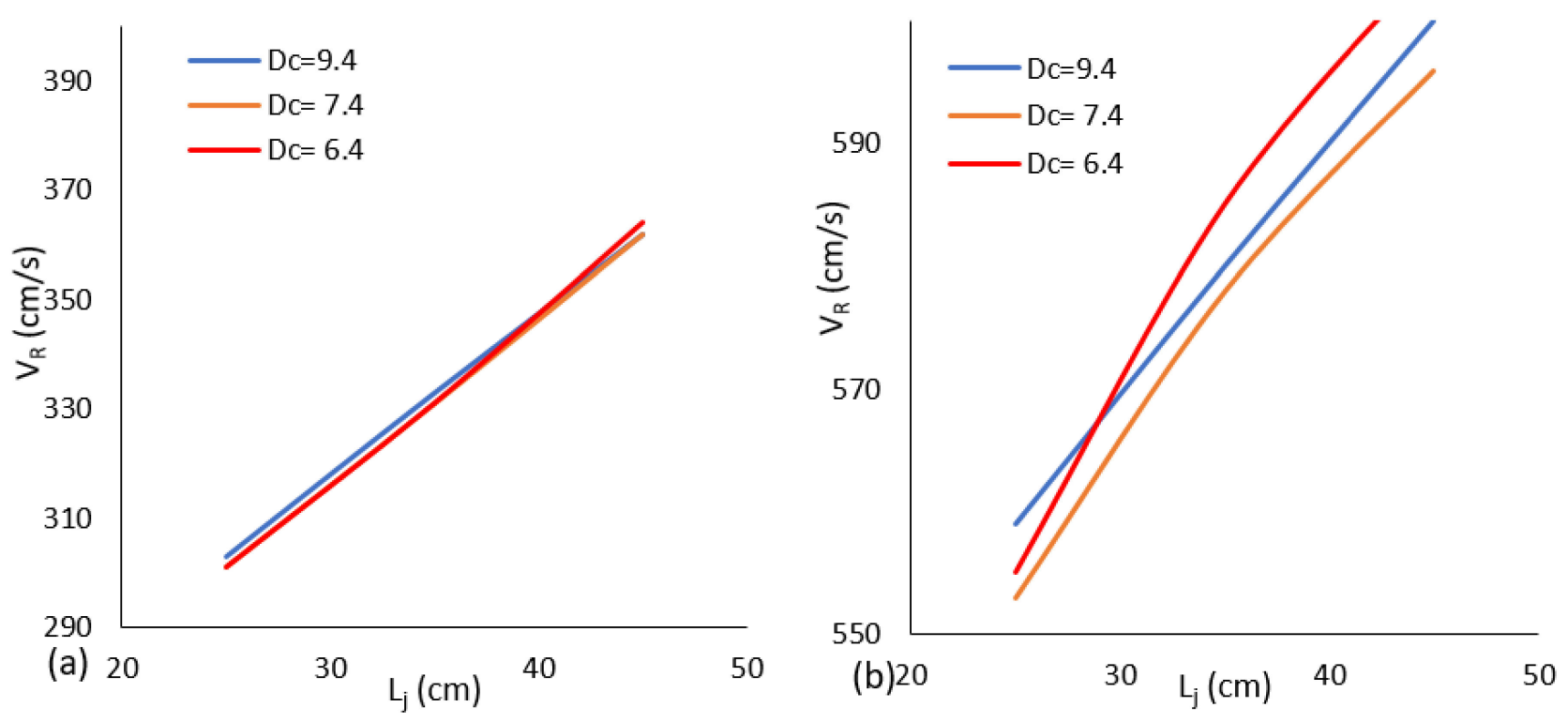

Figure 8. Effect of jet length $\left(L_{j}\right)$ on the velocity $\left(V_{R}\right)$ for different $D_{c}(6.4 \mathrm{~cm}, 7.4 \mathrm{~cm}$ and $9.4 \mathrm{~cm})$ for (a) $\mathrm{Q}_{\mathrm{j}}=167 \mathrm{~cm}^{3} / \mathrm{s}(\mathbf{b}) \mathrm{Q}_{\mathrm{j}}=417 \mathrm{~cm}^{3} / \mathrm{s}$.

\subsection{Comparison between Theoretical and Experimental $H_{R}$ for Different Void Fraction Equations}

As discussed in the previous sections, rise height $\left(\mathrm{H}_{\mathrm{R}}\right)$ values were measured experimentally utilizing CPLJR for given operating conditions. These values were compared against predicted $H_{R}$ values calculated by the momentum model Equation (11) for three void fraction Equations (2), (3) and (6). The air entrainment phenomenon is complex in CPLJR due to many factors such as eddies and vortices [3] and bubble coalescence that impacts the amount of dis/net entrainment rate. This contributes significantly to the void fraction in the downcomer. In general, high jet velocities improve the prediction of $\mathrm{H}_{\mathrm{R}}$ for all three voidage equations. This is due to the minimization of the disentrainment term at such high velocities.

\subsubsection{Effect of Downcomer Submergence Depth $\left(\mathrm{H}_{\mathrm{c}}\right)$ on Rise Height $\left(\mathrm{H}_{\mathrm{R}}\right)$}

To understand which of the void fraction equations were most appropriate, various experimental conditions were used, and the following graphs were generated accordingly. The effect of downcomer submergence $\left(\mathrm{H}_{\mathrm{c}}\right)$ on $\mathrm{H}_{\mathrm{R}}$ is depicted in Figure 9. For a $\mathrm{D}_{\mathrm{c}}$ of $6.4 \mathrm{~cm}$, the model predicts the data satisfactorily at low $\mathrm{H}_{\mathrm{c}}$ with a better prediction for $\mathrm{n}_{1}$ and $\mathrm{n}_{3}$ than $\mathrm{n}_{2}$; this prediction improves with $\mathrm{V}_{\mathrm{j}}$. However, model prediction slightly worsens for all ns as the $\mathrm{H}_{\mathrm{c}}$ increases (doubled in this case). This is maybe due to the disentrainment phenomenon that is prevalent for longer $\mathrm{H}_{c}$ and is challenging to estimate such phenomena theoretically. Furthermore, fluctuations inside the downcomer, due to headspace pressure difference and bubble disentrainment rate [3] also contribute to the change in the $\mathrm{H}_{\mathrm{R}}$ levels that is not accounted for in the model equation.

Figure 10 shows the relationship between $\mathrm{H}_{C}$ and $\mathrm{H}_{R}$. As the downcomer submergence length increases, the rise height also increases for all $D_{c}$. The relationship between $H_{R}$ and $\mathrm{H}_{\mathrm{c}}$ is not a simple monotonic, because of the effect of various operating conditions at the same time $\left(\mathrm{V}_{\mathrm{j}}, \mathrm{L}_{\mathrm{j}}, \mathrm{H}_{\mathrm{c}}\right.$ and $\left.\mathrm{D}_{\mathrm{c}}\right)$. 

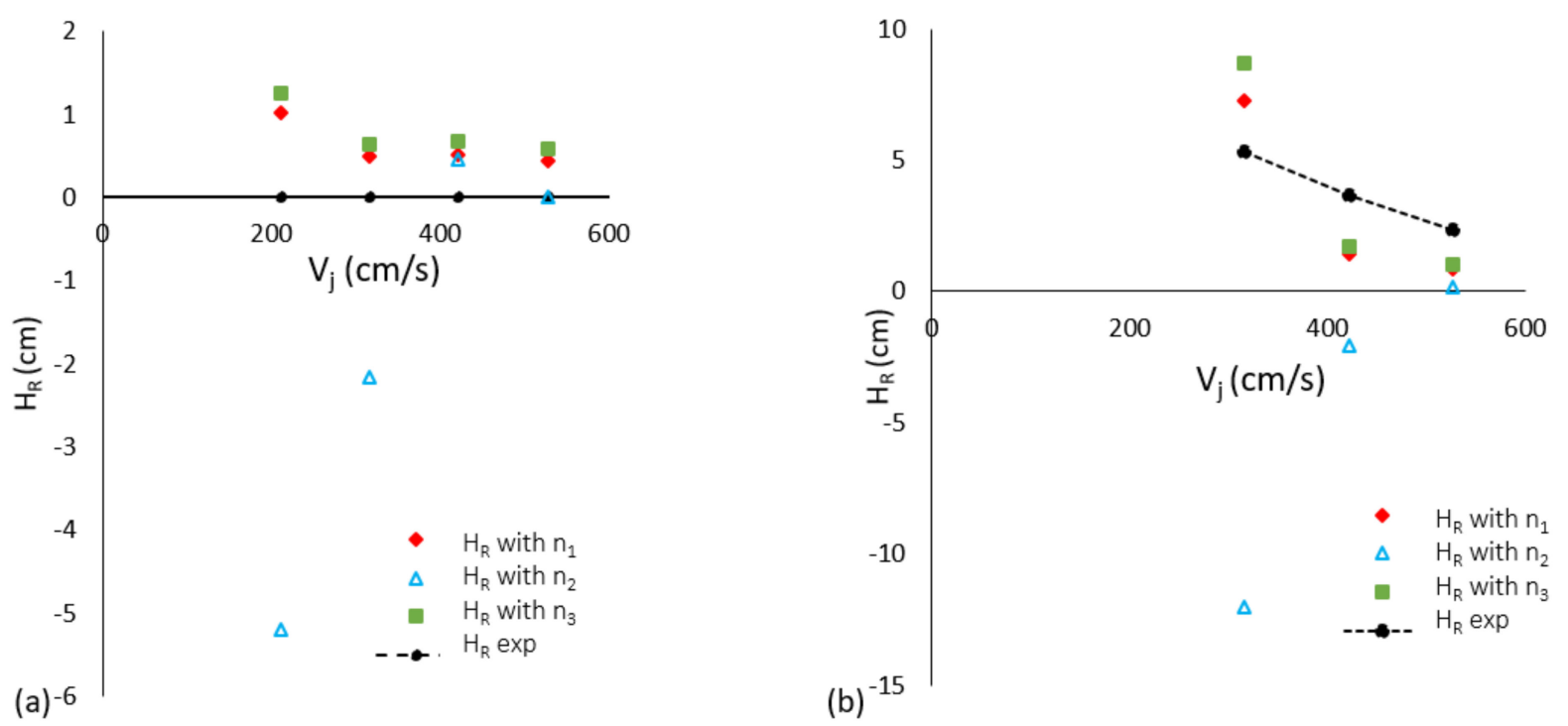

Figure 9. Comparison of experimental $H_{R}$ values with that predicted by model for $D_{c}=6.4 \mathrm{~cm}$ and (a) $\mathrm{H}_{\mathrm{C}}=10 \mathrm{~cm}$ and $(\mathbf{b}) \mathrm{H}_{\mathrm{c}}=20 \mathrm{~cm}$.
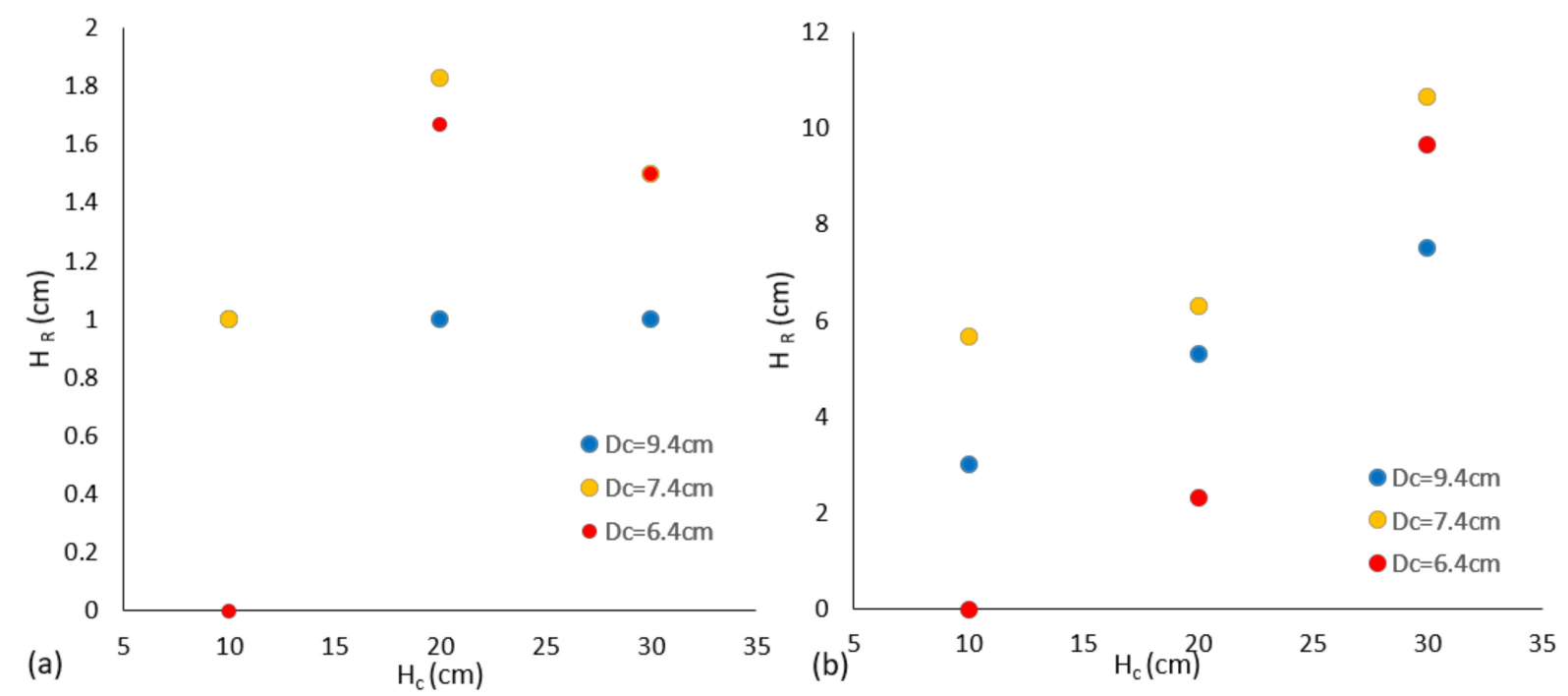

Figure 10. $H_{R}$ vs. $H_{c}$ for three diameters at $(\mathbf{a}) V_{j}=211 \mathrm{~cm} / \mathrm{s}$ and $(\mathbf{b}) V_{j}=527 \mathrm{~cm} / \mathrm{s}$.

\subsubsection{Effect of Diameter of Downcomer (Dc) on Rise Height $\left(\mathrm{H}_{\mathrm{R}}\right)$}

Figure 11 shows that model prediction of $\mathrm{H}_{\mathrm{R}}$ improves with downcomer diameter (Dc) for $n_{1}$ and $n_{3}$. In wider downcomer (9.4 in this case), measured $H_{R}$ values are insignificant $(1-3 \mathrm{~cm})$ as opposed to narrower ones where $H_{R}$ values go up to $6 \mathrm{~cm}$. Furthermore, $H_{R}$ fluctuations were significantly reduced with wider downcomers that may have contributed to the accuracy of the model prediction. This can be seen clearly from Figure $11 \mathrm{~b}$ where $\mathrm{H}_{\mathrm{R}}$ values are insignificant compared to that of smaller downcomer diameters. 


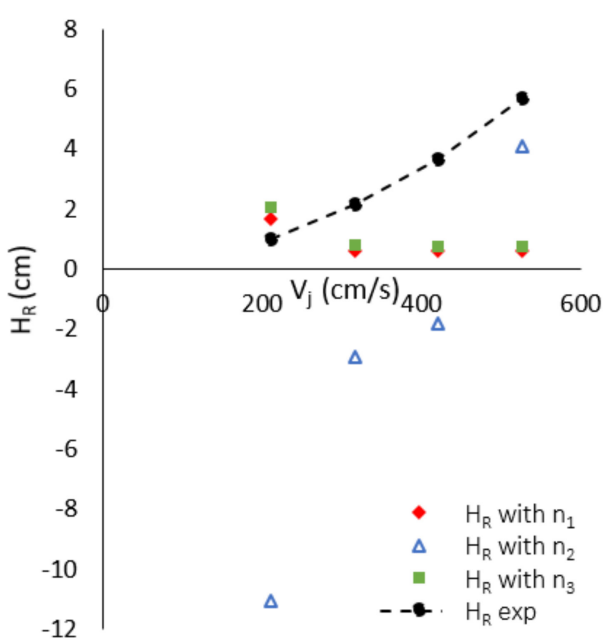

(a)

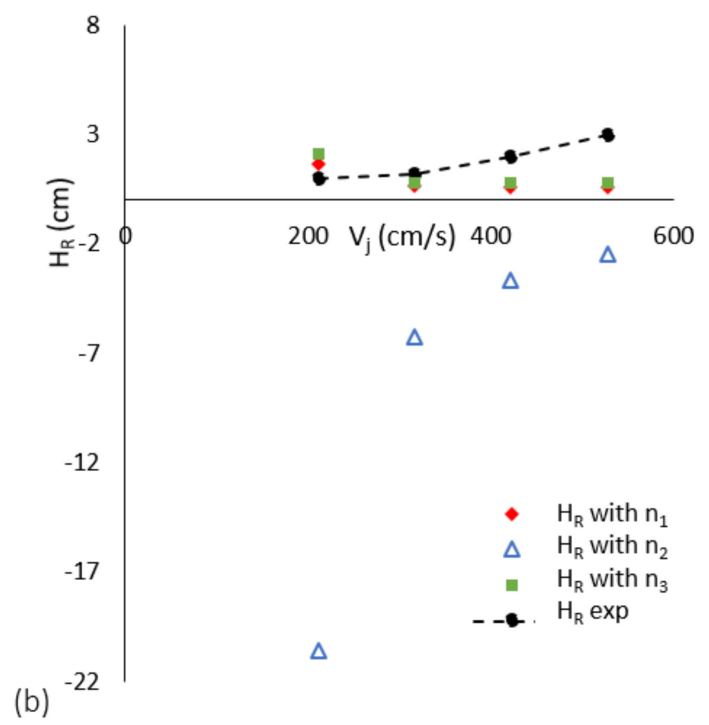

Figure 11. Comparing experimental $H_{R}$ to model generated $H_{R}$ for $(\mathbf{a}) D_{c}=7.4 \mathrm{~cm}$ and $(\mathbf{b}) D_{c}=9.4 \mathrm{~cm}$ at $\mathrm{H}_{\mathrm{C}}=10 \mathrm{~cm}$.

\section{Conclusions}

The current study investigated the effect of $L_{j}$ and $H_{R}$ on the difference between jet velocities of CPLJR at the inception and impingement points $(\Delta V)$. In addition, a momentum balance model was developed to predict the two-phase elevation level inside the downcomer $\left(\mathrm{H}_{\mathrm{R}}\right)$ for three void fraction equations $(\mathrm{n})$. Results showed that $\mathrm{L}_{\mathrm{j}}$ has more of an effect than $H_{R}$ on $\Delta V$ and this effect is more pronounced at low jet velocity. At higher jet velocities, $\mathrm{L}_{\mathrm{j}}$ effect wanes, leading to negligible $(\Delta \mathrm{V})$. The momentum model predicted $\mathrm{H}_{\mathrm{R}}$ satisfactorily for shorter $H_{c}$ and larger $D_{c}$ with better predictions for $n_{1}$ and $n_{3}$ than $n_{2}$.

Author Contributions: Conceptualization, B.S.A.-A.; methodology, B.S.A.-A.; data curation, J.F.; writing-original draft preparation, B.S.A.-A. and J.F.; writing-review and editing, B.S.A.-A. All authors have read and agreed to the published version of the manuscript.

Funding: This work has been funded by Kuwait Foundation for Advancement of Sciences (Grant no: PN1815EV07).

Institutional Review Board Statement: This study did not require any ethical approval.

Informed Consent Statement: Not applicable.

Data Availability Statement: The data in this manuscript has been generated from our laboratory experiments and is contained within the article.

Acknowledgments: The authors would like to thank Kuwait Foundation for Advancement of Sciences for their financial support through project PN1815EV07.

Conflicts of Interest: The authors declare no conflict of interest.

\section{References}

1. Biń, A. Gas entrainment by plunging liquid jets. Chem. Eng. Sci. 1993, 48, 3585-3630. [CrossRef]

2. Chanson, H.; Aoki, S.; Hoque, A. Bubble Entrainment and Dispersion in plunging jet flow: Freshwater vs. seawater. J. Coast. Res. 2006, 22, 664-677. [CrossRef]

3. Al-Anzi, B. Performance of a Novel Confined Plunging Jet Reactor Incorporating an Annular Airlift Column. Ph.D. Thesis, Loughborough University, Loughborough Leicestershire, UK, 2007.

4. Al-Anzi, B. Effect of primary variables on a confined plunging liquid jet reactor. Water 2020, 12, 764. [CrossRef]

5. Chow, A.C.; Srivastava, I.; Adams, E.E.; Al-Rabaie, F.; AL-Anzi, B. Unconfined dense plunging jets used for brine disposal from desalination plants. Processes 2020, 8, 696. [CrossRef]

6. Abdulaziz, Y.I.; Salih, I.K.; Mohammed, T.J. Influences of operating variables on hydrodynamic performance of plunging water jet downflow bubble column. Iraqi J. Chem. Pet. Eng. 2014, 15, 67-80. 
7. Van de Sande, E. Air Entrainment by Plunging Water Jets. Ph.D. Thesis, Technische Hogeschool Delft, Delft, The Netherlands, 1974.

8. Cumming, I.W. The Impact of Falling Liquids with Liquid Surfaces. Ph.D. Thesis, Loughborough University of Technology, Loughborough, UK, 1975.

9. Van De Donk, J.A.C. Water Aeration with Plunging Jets. Ph.D. Thesis, Department of Applied Sciences, Delft University of Technology, Delft, The Netherlands, 1981.

10. Thomas, N.H.; Auton, T.R.; Sene, K.; Hunt, J.C.R. Entrapment and Transport of Bubbles by Plunging Water. In Gas Transport at Water Surfaces; Brutsaert, W., Jirka, G.H., Eds.; Reidel: Dordrecht, The Netherlands, 1984; pp. 255-268.

11. Yagasaki, T.; Kuzuoka, T. Surface entrainment of gas by plunging liquid jets. Res. Rep. Kogakuin Univ. 1979, 47, 77-85.

12. Clanet, C.; Lasheras, J.C. Depth of penetration of bubbles entrained by a plunging water jet. Phys. Fluids 1997, 9, 1864-1866. [CrossRef]

13. Baylar, A.; Emiroglu, M.E. Air Entrainment and oxygen transfer in a venture. Proc. Inst. Civ. Eng. Water Marit. Eng. 2003, 156, 249-255. [CrossRef]

14. Bagatur, T.; Baylar, A.; Sekerdag, N. The effect of nozzle on air entrainment by plunging water jets. Water Qual. Res. J. Can. 2002, 37, 599-612. [CrossRef]

15. Ohkawa, A.; Kusabiraki, D.; Kawai, Y.; Sakai, N. Some flow characteristics of a vertical liquid jet system having downcomers Chem. Eng. Sci. 1986, 41, 2347-2361. [CrossRef]

16. Bayly, A.E.; Rielly, C.D.; Evans, G.M.; Hazell, M. The rate of expansion of a confined submerged jet. In Proceedings of the 20th Australasian Chemical Engineering Conference, Chemeca 92: The Impact of Government Policy on the Process Industries, Official Conference Proceedings, Canberra, Australia, 1 January 1992; Royal Australian Chemical Institute: Canberra, Australia, 1992; pp. 119-126. Available online: https://search.informit.org/doi/epdf/10.3316/informit.842451936244500 (accessed on 13 November 2021).

17. Evans, G.M.; Jamson, G.J.; Rielly, C.D. Free jet expansion and gas entrainment characteristics of a plunging liquid jet. Exp. Therm. Fluid Sci. 1996, 12, 142-149. [CrossRef]

18. Cumming, I.W.; Rielly, C.D.; Mason, A.J. Hydraulic performance of an annular plunging jet reactor. Trans. Inst. Chem. Eng. 2002, 80, 543-549. [CrossRef]

19. Low, K.C. Hydrodynamics and Mass Transfer Studies of a Confined Plunging Jet. Ph.D. Thesis, Department of Chemical Engineering, Loughborough University, Loughborough, UK, 2003.

20. Bertola, N.; Wang, H.; Chanson, H. Air Bubble Entrainment at Vertical Plunging Jets: A Large-Scale Experimental Study; Hydraulic Model Report No. CH104/17; The University of Queensland, School of Civil Engineering: Brisbane, Australia, 2017; ISBN 978-174272-181-1.

21. Whitehead, A. PDP Project Report; Department of Chemical Engineering, Loughborough University: Loughborough, UK, 2002.

22. Srivastava, I.; Adams, E.E.; Al-Anzi, B.A.; Chow, A.A.; Han, J. Confined plunging liquid jets for dilution of brine from desalination plants. Processes 2021, 9, 856. [CrossRef]

23. Yamagiwa, K.; Kusabiraki, D.; Ohkawa, A. Gas holdup and gas entrainment rate in a downflow bubble column with gas entrainment by a liquid jet operating at high liquid throughput. J. Chem. Eng. Jpn. 1990, 23, 343-348. [CrossRef]

24. Miwa, S.; Moribe, T.; Tsutstumi, K.; Hibiki, T. Experimental Investigation of air entrainment by vertical plunging liquid jets. Chem. Eng. Sci. 2018, 181, 251-263. [CrossRef]

25. Chanson, H.; Lee, J.F. Characteristics of Plunging Breaking Waves; RESEARCH REPORT No. CE 150; Department of Civil Engineering, The University of Queensland: Brisbane, Australia, 1995.

26. Zuber, N.; Findlay, J.A. Average volumetric concentration in two-phase flow systems. J. Heat Transf. 1965, 87, 453-468. [CrossRef]

27. Atkinson, B.W.; Jameson, G.J.; Nguyen, A.V.; Evans, G.M. Increasing gas-liquid contacting using a confined plunging liquid jet. J. Chem. Technol. Biotechnol. 2003, 78, 269-275. [CrossRef]

28. Clark, N.N.; Flemmer, R.L.C. On vertical downward two-phase flow. Chem. Eng. Sci. 1984, 39, 170-173. [CrossRef]

29. Qu, X.; Khezzar, L.; Danciu, D.; Labois, M.; Lakehal, D. Characterization of plunging liquid jets: A combined experimental and numerical investigation. Int. J. Multiph. Flow 2011, 37, 722-731. [CrossRef]

30. Kramer, K.; Wieprecht, S.; Terheiden, K. Penetration depth of plunging liquid jets-A data driven modelling approach. Exp. Therm. Fluid Sci. 2016, 76, 109-117. [CrossRef]

31. Wang, H.; Bertola, N.; Chanson, H. 2016 Bubble entrainment in vertical plunging jets. In Proceedings of the 20th Australasian Fluid Mechanics Conference, Perth, Australia, 5-8 December 2016. 